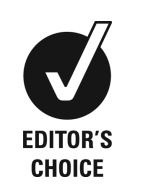

${ }^{1}$ Infectious Diseases Unit, The Canberra Hospital, Canberra, Australian Capital Territory, Australia

${ }^{2}$ Department of Immunology, The Canberra Hospital,

Canberra, Australian Capital Territory, Australia

${ }^{3}$ Australian National University (ANU) Medical School, Canberra, Australian Capital Territory, Australia

Correspondence to

Dr Ray Mun Koo,

raymun@gmail.com

Accepted 18 December 2014

\title{
Granulicatella adiacens subacute bacterial endocarditis as the underlying cause of type II mixed cryoglobulinaemia
}

\author{
Benjamin W C Sim, ${ }^{1}$ Ray Mun Koo, ${ }^{1}$ Carolyn Hawkins, ${ }^{2,3}$ Francis Bowden, ${ }^{1,3}$ \\ Ashley Watson ${ }^{1,3}$
}

\section{SUMMARY}

A 57-year-old man with type II mixed cryoglobulinaemia presented to the emergency department with a history of worsening lethargy, malaise and non-drenching night sweats in a relapsing-remitting pattern. He was diagnosed with type II mixed cryoglobulinaemia 7 months ago following episodes of fever, night sweats, lethargy and malaise associated with a non-blanching, purpuric, raised erythematous rash that responded partially to immunosuppressive therapy and short courses of oral antibiotics. A single blood culture then yielded Granulicatella adiacens which was reported as a possible contaminant and therefore, not pursued. Despite numerous other investigations, the underlying cause of his type II cryoglobulinaemia remained undetermined. On his current presentation, the physical examination revealed signs of infective endocarditis. Two further blood cultures grew $G$. adiacens. The diagnosis of infective endocarditis was established on a transoesophageal echocardiography, and the subsequent antibiotic and surgical therapy resulted in complete remission of his type II mixed cryoglobulinaemia.

\section{BACKGROUND}

As $90 \%$ of cases of cryoglobulinaemia have a known underlying cause, the inciting source must be found and aggressively treated. ${ }^{1}$ The patient had documented Granulicatella adiacens bacteraemia which was labelled as a potential contaminant leading to delay in start of appropriate treatment. A subsequent diagnosis of $G$. adiacens subacute bacterial endocarditis (SBE) was eventually made and treated, which resulted in remission of the type II mixed cryoglobulinaemia.

SBE has long been associated with cryoglobulinaemia, but to the best of our knowledge there has been no published association between $G$. adiacens $\mathrm{SBE}$ and type II mixed cryoglobulinaemia.

\section{CASE PRESENTATION}

A 57-year-old man presented to the emergency department with a worsening history of persistent fever associated with lethargy, malaise and nondrenching night sweats in a relapsing-remitting pattern. The illness began 7 months prior, when the patient was diagnosed with a mild respiratory infection that was treated with amoxycillin/clavulanic acid. Over the following 2 months-and despite further oral antibiotic treatment-he continued to experience fever, night sweats, lethargy and malaise. These symptoms were soon accompanied by dry cough, anorexia and weight loss recurring fortnightly alongside a new nonblanching, purpuric, raised erythematous rash predominantly involving his lower limbs. The patient had not taken any further antibiotic treatment in the 2 months leading up to the presentation. These features lead to a clinical and laboratory diagnosis of type II mixed cryoglobulinaemia (table 1). Antinuclear antibodies (ANA), rheumatoid factor and antineutrophil cytoplasmic antibodies (ANCA) were not detected. A punch biopsy of one of the skin lesions revealed features of leukocytoclastic vasculitis. A single blood culture taken grew $G$. adiacens, which was reported by the laboratory as a possible contaminant. Serology for HIV, hepatitis B and hepatitis $\mathrm{C}$ was negative. CT of the neck, chest and abdomen did not reveal any evidence for a malignancy.

The patient was treated with prednisolone $25 \mathrm{mg}$ daily and methotrexate $10 \mathrm{mg}$ weekly, which resulted in a temporary remission of the rash. Despite this treatment the symptoms relapsed, leading to additional treatment with roxithromycin and then clarithromycin. A partial symptomatic response to this treatment was followed by another relapse.

On presentation, physical examination revealed an oral temperature of $37.5^{\circ} \mathrm{C}$ and blood pressure of $145 / 60 \mathrm{~mm} \mathrm{Hg}$. Cardiovascular examination identified splinter haemorrhages on fingers and toes, water hammer pulse, an early diastolic murmur and femoral pistol shot pulses. There were no palpable lymph nodes or hepatosplenomegaly. There were no visible skin lesions. Neurological examination was normal.

\section{INVESTIGATIONS}

Two further blood cultures again revealed G. adiacens. The significance of the previous blood culture result was reconsidered and endocarditis was now suspected. The patient was empirically treated with benzylpenicillin and gentamicin. Transoesophageal echocardiography revealed a $10 \mathrm{~mm}$ vegetation on the non-coronary cusp of the aortic valve (figure 1), associated with severe aortic regurgitation and an ejection fraction of $73 \%$.

\section{TREATMENT}

The patient ultimately received 6 weeks of benzylpenicillin and was gradually weaned off 
Table 1 Serum protein electrophoresis levels, serum and plasma immunoglobulin levels, complement levels and cryoglobulin type at time of initial presentation (values in bold indicated a reading outside the normal reference range)

\begin{tabular}{ll}
\hline Protein electrophoresis (serum) & \\
Total protein (g/L; 60-80) & 85 \\
Albumin (g/L; 38-50) & 37 \\
$\alpha-1-G l o b u l i n(g / L ; 2-4)$ & 2 \\
$\alpha-2-G l o b u l i n(g / L ; 5-11)$ & 15 \\
$\beta$ Globulin (g/L; 5-12) & 8 \\
Y Globulin (g/L; 8-16) & 23 \\
Immunoglobulins (serum/plasma) & \\
IgG (g/L; 7-16) & 18.1 \\
IgA (g/L; 0.70-4.00) & 2.57 \\
IgM (g/L; 0.4-2.3) & 4.6 \\
Complements (serum/plasma) & \\
C3 (g/L; 0.82-1.85) & 1.55 \\
C4 (g/L; 0.14-0.42) & 0.27 \\
Cryoglobulin ID & \\
Monoclonal & IgM $\lambda$ \\
Polyclonal & DETECTED \\
Classification & Type II \\
Total protein (g/L) & 0.08 \\
\hline
\end{tabular}

prednisolone. Repeat blood cultures 11 days after the course of treatment were negative. Subsequently, the patient underwent aortic valve replacement using a $25 \mathrm{~mm}$ Carpentier-Edwards Perimount biological prosthesis, with an unremarkable postoperative course. Histopathological examination of valve tissue showed myxoid degeneration, focal calcification and chronic inflammation.

\section{OUTCOME AND FOLLOW-UP}

On further testing, subsequent blood cultures have been negative, while cryglobulin levels have remained undetectable 7 months post-completion of antibiotic therapy (table 2). He remains well in the community with no evidence of disease recurrence.

\section{DISCUSSION}

Granulicatella species is an uncommon cause of bacterial endocarditis, with 18 cases of Granulicatella endocarditis reported to date. $^{2} 3$ The most common species is G. adiacens which typically affects cardiac valves and pacemaker leads. ${ }^{2}$ Granulicatella endocarditis has also been reported to have a high relapse rate, with a mortality of $9.5 \% .^{2}$

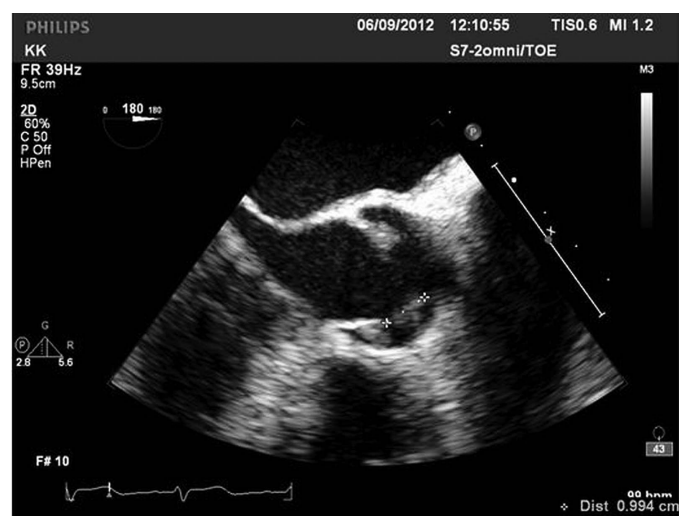

Figure 1 Transoesophageal echocardiography revealing a $10 \mathrm{~mm}$ vegetation on the non-coronary cusp of the aortic valve.
Table 2 Serum protein electrophoresis levels, serum and plasma immunoglobulin levels, complement levels and cryoglobulin type and levels before and after treatment (values in bold indicated a reading outside the normal reference range)

\begin{tabular}{|c|c|c|}
\hline & \multicolumn{2}{|c|}{ Intravenous antibiotic therapy } \\
\hline & Before & After \\
\hline \multicolumn{3}{|l|}{ Protein electrophoresis (serum) } \\
\hline Total protein (g/L; 60-80) & 85 & 76 \\
\hline Albumin (g/L; 38-50) & 37 & 44 \\
\hline$\alpha-1-$ Globulin (g/L; 2-4) & 2 & 1 \\
\hline$\alpha-2-G l o b u l i n(g / L ; 5-11)$ & 15 & 10 \\
\hline$\beta$ Globulin (g/L; 5-12) & 8 & 8 \\
\hline$\Upsilon$ Globulin (g/L; 8-16) & 23 & 4 \\
\hline \multicolumn{3}{|c|}{ Immunoglobulins (serum/plasma) } \\
\hline $\lg G(g / L ; 7-16)$ & 18.1 & 10.9 \\
\hline $\lg A(g / L ; 0.70-4.00)$ & 2.57 & 1.71 \\
\hline $\lg M(g / L ; 0.4-2.3)$ & 4.6 & 2.2 \\
\hline \multicolumn{3}{|l|}{ Complements (serum/plasma) } \\
\hline C3 (g/L; 0.82-1.85) & 1.55 & 1.24 \\
\hline C4 (g/L; 0.14-0.42) & 0.27 & 0.19 \\
\hline \multicolumn{3}{|l|}{ Cryoglobulin ID } \\
\hline Monoclonal & $\lg M \lambda$ & - \\
\hline Polyclonal & DETECTED & NOT DETECTED \\
\hline Classification & Type II & - \\
\hline Total protein $(\mathrm{g} / \mathrm{L})$ & 0.08 & - \\
\hline
\end{tabular}

Granulicatella species were previously named nutritionallyvariant streptococci due to their requirement of pyridoxal or other agents in standard media for laboratory isolation. ${ }^{2}$ These Gram-positive cocci are facultative anaerobes that are part of normal oral flora but are also associated with dental plaques, endodontic infections and infections involving the musculoskeletal and central nervous systems. ${ }^{2}$ Before pyridoxal dependence was considered, these streptococci were difficult to culture and probably often under-reported in diagnostic laboratories. ${ }^{4}$ Although Granulicatella has been proposed as one of the causes of 'culture-negative' endocarditis, ${ }^{4}$ a reported series of 348 cases revealed only one case caused by Granulicatella infection. ${ }^{5}$

The precise nature of immune activation in SBE is not fully understood, but it is believed that the protracted course of the condition leads to constant antigenic stimulation, which then stimulates the clonal expansion of B cells. This process promotes the production of several classes of antibodies, such as rheumatoid factor, ANA, cryoglobulins and ANCA. ${ }^{6}$

Cryoglobulins are immunoglobulins which precipitate at temperatures below $37^{\circ} \mathrm{C}$ and redissolve after rewarming; their presence in serum is defined as cryoglobulinaemia. Cryoglobulinaemia is commonly present as a triad of purpura, arthralgia and weakness, although features of hyperviscosity syndrome and vasculitis may be apparent. ${ }^{1}$ Cryoglobulins are categorised according to the Brouet classification (table 3$){ }^{7}$ with type II cryoglobulins being closely associated with persistent viral infections, most notably chronic hepatitis $\mathrm{C}$ virus (HCV) infection. ${ }^{1}$ Much of our current understanding of cryoglobulin pathogenesis is based on B-cell mediated immune responses in $\mathrm{HCV}$ infection which drive cryoglobulin generation via clonal B-cell proliferation. ${ }^{1}$

As up to $90 \%$ of cases of cryoglobulinaemia have a known underlying cause, its aetiology has to be determined for start of effective treatment. ${ }^{1}$ When the cause of cryoglobulinaemia is 
Table 3 Brouet classification of cryoglobulinaemia

\begin{tabular}{ll}
\hline Types of Cryoglobulinaemia & Immunoglobulins \\
\hline Type I & Monoclonal IgM or IgG \\
Mixed & \\
Type II & Monoclonal IgM and Polyclonal IgG \\
Type III & Polyclonal IgM and Polyclonal IgG \\
\hline
\end{tabular}

uncertain, treatment strategies include immunosupression, antiviral treatment or biological therapies, and are dependent on disease severity and the number of organ involvement. ${ }^{1}$ Approximately $50 \%$ of cases have good prognosis with a benign clinical course while for males, age greater than 60 years, type 2

\section{Learning points}

- The presence of cryoglubinaemia warrants further investigation as an underlying aetiology is likely to be present.

- Cryoglobulinaemia treatment is focused on treating the underlying cause. Treatment options for cryoglobulinaemia of unknown aetiology include immunosupressive, antiviral treatment or biological therapies.

- The presence of Granulicatella species in blood cultures is always significant. Although uncommon, subacute bacterial endocarditis has to be considered as a possible cause. cryoglobulinaemia and chronic HCV infection are associated with poor outcomes. ${ }^{1}$

The presence of cryoglobulins in patients with infective endocarditis is not uncommon. Hurwitz et $a l^{8}$ demonstrated that the prevalence of cryoglobulinaemia in 'infective endocarditis' was as high as $90 \%$, which is consistent with findings from previous studies. ${ }^{9}$ The main culprit organisms were Group D Streptococcus and Staphylococcus aureus, while the serum cryoglobulins were typically of a mixed type. ${ }^{8}$

Competing interests None.

Patient consent Obtained.

Provenance and peer review Not commissioned; externally peer reviewed.

\section{REFERENCES}

1 Ramos-Casals M, Stone JH, Cid MC, et al. The cryoglobulinaemias. Lancet 2012;379:348-60.

2 Cargill JS, Scott KS, Gascoyne-Binzi D, et al. Granulicatella infection: diagnosis and management. J Med Microbiol 2012;61:755-61.

3 Shailaja TS, Sathiavathy KA. Infective endocarditis caused by Granulicatella adiacens. Indian Heart J 2013:65:447-9.

4 Brouqui P, Raoult D. Endocarditis due to rare and fastidious bacteria. Clin Microbiol Rev 2001;14:177-207.

5 Houpikian P, Raoult D. Blood culture-negative endocarditis in a reference center: etiologic diagnosis of 348 cases. Medicine (Baltimore) 2005;84:162-73.

6 De Corla-Souza A, Cunha BA. Streptococcal viridans subacute bacterial endocarditis associated with antineutrophil cytoplasmic autoantibodies (ANCA). Heart Lung 2003;32:140-3.

7 Brouet JC, Clauvel JP, Danon F, et al. Biologic and clinical significance of cryoglobulins: a report of 86 cases. Am J Med 1974;57:775-8.

8 Hurwitz D, Quismorio FP, Friou GJ. Cryoglobulinaemia in patients with infectious endocarditis. Clin Exp Immunol 1975;19:131-41.

9 Dreyfuss F, Librach G. Cold precipitable serum globulins ('cold fractions, cryoglobulins') in subacute bacterial endocarditis. J Lab Clin Med 1952:40:489-97.

Copyright 2015 BMJ Publishing Group. All rights reserved. For permission to reuse any of this content visit

http://group.bmj.com/group/rights-licensing/permissions.

BMJ Case Report Fellows may re-use this article for personal use and teaching without any further permission.

Become a Fellow of BMJ Case Reports today and you can:

- Submit as many cases as you like

- Enjoy fast sympathetic peer review and rapid publication of accepted articles

- Access all the published articles

- Re-use any of the published material for personal use and teaching without further permission

For information on Institutional Fellowships contact consortiasales@bmjgroup.com

Visit casereports.bmj.com for more articles like this and to become a Fellow 